\title{
Los procesos de patrimonialización en la re-actualización de la nación: la Comisión Nacional de Museos, Monumentos y Lugres Históricos en Argentina
}

\author{
Heritage processes in the re-actualization of nation: \\ National Commission of Museums, Monuments and \\ Historic Assets in Argentina
}

\author{
Cecilia Pérez Winter ${ }^{1}$
}

\begin{abstract}
RESUMEN
La construcción y reactualización de la idea de nación precisa de dispositivos que determinen qué elementos (materiales y simbólicos) y sujetos se incluyen en ella. En este marco, nos interesa indagar en la patrimonialización nacional como un tipo de dispositivo. Proponemos, a partir de este proceso, identificar y analizar: (i) los principales actores involucrados; (ii) los elementos, sujetos y lugares seleccionados; y (ii) las implicaciones simbólicas territoriales. Como caso empírico, examinamos la actuación de la Comisión Nacional de Museos, Monumentos y Lugares Históricos (CNMMLH) de Argentina, organismo encargado de orientar el reconocimiento de los potenciales patrimonios nacionales entre 1984-1993, lapso en el cual se inicia una nueva etapa de gestión con el restablecimiento del régimen democrático en el país. Así, concluimos que la configuración de patrimonios nacionales activa versiones sobre el pasado, identidades y territorios que permiten consolidar un tipo de "comunidad imaginada" y sus límites simbólicos geográficos.
\end{abstract}

Palabras Claves: Patrimonio, Nación, Comisión Nacional de Monumentos, Museos y Lugares Históricos.

\section{ABSTRACT}

The construction and actualization of the notion of nation needs mechanism to assist in the selection of which elements (materials and symbolic) and subjects are going to be included in it. In this context, we are interested in inquiring Heritage process as one of such mechanism. We propose, through the study of Heritage construction, to identified and analyze: (i) the main actors involved; (ii) the elements, subjects and places chosen, and (iii) the symbolic spatial implications. We discuss these issues by examining the National Commission of Museums, Monuments and Historic Assets (CNMMLH) of Argentina, institution in charge of national heritage recognition, between 1984-1993, term, moment in which democracy is reestablish in the country. We conclude that national heritage activates versions about the past, identities and territories which contribute to consolidate a type of "imagined community" and its geographical symbolic limits.

Keywords: Heritage, Nation, National Commission of Museums, Monuments and Historic Assets. 
La idea de nación -y nacionalismo- ha sido largamente discutida. Así como algunos autores la conciben como una narrativa que pierde sus orígenes en el mito del tiempo (Bhabha, 2000: 1), otros proponen que se trata de un artefacto cultural construido por una clase determinada, caracterizándola además como una comunidad política imaginada y limitada. Es decir, la nación posee fronteras finitas y aunque sus miembros no se conocen entre sí, los une un vínculo horizontal y fraternal de compañerismo profundo (Anderson, 2011). Este sentimiento de pertenencia -y de lealtad-, sería tan fuerte como para llevar a los miembros de una nación a dar la vida por ella. Asimismo, ese sentimiento es el que posibilita conformar un vínculo entre esa "comunidad imaginada" (homogénea) y un Estado, que, mediante legitimación política, busca convencer a la población en general que todos sus habitantes son representados por él como una unidad cultural (Anderson, 2011; Gellner, 2001). El Estado también actúa como el agente que monopoliza el ejercicio legítimo de la fuerza para mantener el orden dentro de un territorio (Gellner, 2001) y como un ente que debe garantizar la libertad de sus ciudadanos (Anderson, 2011). Asimismo, el sentimiento de pertenencia es lo que legitima y consolida los lazos entre una comunidad y un territorio (Radcliffe y Westwood, 2005).

La nación es una construcción ideológica, política y cultural en la que se recupera/selecciona elementos, lugares, expresiones de grupos socioculturales y étnicos pre-existentes para conformarla como tal (Anderson, 2011; Gellner, 2001; Hobsbwam, [1990] 2000), a partir de la creación de símbolos -banderas, himnos nacionales, patrimonios-, prácticas y otras acciones, como la conmemoración de fechas "patrias" (Eriksen, 2010; Pagano y Rodríguez, 2014). Por lo tanto, para la construcción y persistencia de un Estado-Nación es necesario determinar, por una parte, qué elementos materiales y simbólicos se incluyen. Por otra parte, identificar quiénes -y mediante qué dispositivos (discursos, normativas, patrimonializaciones)- se logra reforzar/actualizar el sentimiento de pertenencia/lealtad. Utilizamos el concepto de dispositivo en el sentido foucaultiano, es decir, como un conjunto heterogéneo de elementos -discursos, instituciones, normas, instalaciones-, creado en un contexto espacial y temporal determinado, que funciona como una red de saber, poder y subjetividad (García Fanlo, 2011). Así, el patrimonio como dispositivo puede ser utilizado tanto como una forma de ejercer poder sobre ciertos sujetos, geografías, pasados, prácticas y saberes; como de selección y legitimación -resignificación y apropiación- de ciertos referentes identitarios/culturales.

A su vez, y como señala Billig (2002), la actualización del sentido de lealtad hacia la nación no solo ocurre en momentos de crisis -cuando tal vez se observa con mayor claridad- sino también durante la experiencia cotidiana, es decir, en aquellos "tiempos entremedio" (in between times, Billig, 2002: 6). Por ello, consideramos que la idea de Nación -junto a su materialización territorial- es un proceso dinámico que no ocurre solo en el momento de su gestación, sino que es un proceso de continua configuración, en el que se despliegan una serie de estrategias para mantenerse y resignficarse. En este marco, nos preguntamos ¿cómo -y entre qué actores- se determina qué elementos y sujetos se incluyen/excluyen en la idea de nación?, ¿qué dispositivos se implementan desde el Estado para actualizar la idea de nación?, ¿cómo se construye y/o resignifica el vínculo entre una versión de pasado y presente?, ¿qué implicaciones territoriales producen estos procesos?

Es a partir de la conformación de los Estados-Nación europeos durante el siglo XVIII que se comienza a pensar al patrimonio (cultural) como un "acervo" colectivo (Giménez, 1982; Mantecón, 
1998). Por ello, concordamos con aquellos autores que dan cuenta de la relevancia que poseen los procesos de patrimonialización en la configuración y legitimación de los Estados-Nación (Arantes, 1984; Eriksen, 2010; Florescano, 1993; Poulot, 2009). Así, ante lo expuesto, proponemos como objetivo general indagar la patrimonialización como dispositivo que permite construir/actualizar la idea de nación. En ese contexto, y como objetivos específicos, planteamos identificar y analizar: (i) los actores centrales que participan; (ii) los elementos, sujetos y lugares seleccionados; y (iii) las implicaciones simbólicas territoriales del proceso de patrimonialización. Como caso empírico, examinamos la actuación de la Comisión Nacional de Museos, Monumentos y Lugares Históricos (CNMMLH) de Argentina, organismo encargado de orientar las patrimonializaciones nacionales en el país ${ }^{2}$. Si bien haremos un recorrido sobre su origen y primeras acciones -a modo de contextualización y con fines comparativos- nos interesa focalizar el estudio en el periodo 1984-1993, lapso en el cual se inicia una nueva etapa de gestión con el restablecimiento del régimen democrático en el país. Cabe señalar que actualmente la CNMMLH se denomina Comisión Nacional de Monumentos, Lugares y Bienes Históricos. Sin embargo, como el análisis propuesto toma el periodo anterior al 2015 -año del cambio de nomenclatura mediante la Ley Nacional 27.103- optamos por hacer referencia a su antiguo nombre.

Para la realización de esta investigación se examinaron diversos documentos producidos por la CNMMLH -Boletines (1939-1958), Actas (1983-1985), Cartas Informativas (1985-1999), normativas y declaratorias (1940-2015)- consultados en el archivo de la CNMMLH y la biblioteca de la Academia Nacional de Historia, localizados en la Ciudad Autónoma de Buenos Aires. Es importante aclarar que en los Boletines se publicaba información sobre la gestión de la CNMMLH como: informes de viajes de trabajos de campo que realizaban algunos de los miembros, las actas de las reuniones, las declaratorias realizadas, breves investigaciones sobre temáticas vinculadas al ámbito patrimonial de interés, entre otras cosas. En la década de 1950 se interrumpió la impresión de los Boletines. No obstante, existen otros documentos que permiten reconstruir la actuación de la CNMMLH en los años sucesivos como los libros de Actas escritos a mano y las Cartas Informativas que se publicaron a partir de la década de 1980. Asimismo, las declaratorias son los instrumentos legales que implementa la CNMMLH, a partir de un Decreto o Ley Nacional aprobado por el Poder Ejecutivo, para reconocer y justificar la selección y patrimonialización de un determinado "bien". Por otra parte, las informaciones sobre la cantidad y tipo de bienes reconocidos por la CNMMLH fueron obtenidas y facilitadas por la propia institución, las cuales fueron provistas en una tabla de Excel conteniendo las siguientes variables: ubicación geográfica (provincia, ciudad, dirección), categoría patrimonial, descripción del bien y legislación (número y fecha) emitida por el Poder Ejecutivo Nacional por el cual el bien fue declarado/protegido como patrimonio nacional.

El artículo está estructurado de la siguiente forma: primero, introducimos los lineamientos teóricos construidos e implementados en el desarrollo de este trabajo; segundo, presentamos una reseña de la conformación de la CNMMLH para, posteriormente, analizar y comparar su actuación en periodo elegido (1984-1993). Por último, exponemos las consideraciones finales desprendidas del análisis realizado. 


\section{La patrimonialización en la construcción de lo nacional}

Para Renan (2000) la nación es la culminación de un largo camino de esfuerzos, sacrificios y devoción que requiere -para existir y sobrevivir- "olvidar" ciertos hechos trágicos/violentos que ocurrieron durante la historia de su gestación. Sin embargo, también precisa de la conmemoración de cosas en común como un pasado heroico de "glorias" y "grandes hombres". Ello contribuiría a dar lugar a la existencia de la nación como un "plebiscito diario" en el que se establece anteponer la voluntad colectiva sobre la individual (Renan, 2000: 19). A su vez, aunque se la reconozca como un invento moderno, se tiende a construir la idea de nación como vernácula para lograr su legitimación (Gellner, 2001). Pensar la nación bajo esas características -como las planteadas por Renan y Gellner-favorece a la conformación de un mito -como señala Bhabha- de la identidad nacional arraigado en un territorio de tipo "ancestral". Ello permite pensar la existencia de una "comunidad imaginada" (Anderson, 2011) mediante la configuración de una "patria" propia y una "tierra natal" (homeland) única y colectiva. Por lo cual, todo aquello que forma parte de ese territorio nacional se torna sagrado y perteneciente a los miembros de la nación (Smith, 1991). Estos vínculos de pertenencia entre una nación, un territorio y una comunidad -que comparten una versión de identidad y pasado comunes- no emerge espontáneamente, sino que debe ser construido y legitimado. En este sentido, Collado (2015) sostiene que el patrimonio es la prueba palpable de la existencia de lazos con un pasado fuertemente asociado a los orígenes.

Por ello, concebimos a la patrimonialización como un dispositivo que permite reforzar y reactualizar la idea de nación. Es decir, como un proceso de construcción social en la cual ciertos actores -en particular los que se posicionan como detentadores de la voz "autorizada"-, seleccionan e impulsan la significación/sacralización y jerarquización de versiones de pasado e identidades -homogéneas-, símbolos y prácticas (Eriksen, 2010; Pagano y Rodríguez, 2014). Asimismo, entendemos como "voz autorizada" a quien se reconoce, y es reconocida, dentro de un grupo al cual pertenece y/ representa (Goodenough, 1965) como aquella persona habilitada -en parte por el capital simbólico acumulado- para producir un tipo de discurso, que en este caso consistiría en conocimientos sobre historia-patrimonio. A su vez, porque en términos de Bourdieu (1972), posee una eficacia performativa, con la cual detenta cierto poder para exponer discursos que generen consenso con otros actores involucrados en la patrimonialización para legitimar los patrimonios configurados (Prats, 2004; Smith, 2006). Y aunque diversos actores se involucran en la construcción del patrimonio, el Estado tiende a colocarse como el mayor impulsor de este proceso al contar con los recursos necesarios para lograrlo (Florescano, 1993; García Canclini, 2010; Prats, 2004).

La selección y jerarquización de determinados elementos/sujetos/lugares por sobre otros, como patrimonios (Prats, 2004), permitirá evocar un sentimiento de pertenencia (Gellner, 2001), de "comunidad imaginada" (Anderson, 2011) asociada a un territorio (Ortega Valcárcel, 1998; Radcliffe y Westwood, 2005). Por lo tanto, la patrimonialización opera como dispositivo que establece qué elementos, sujetos y territorios se incluyen -y bajo qué valores- en la idea de nación o cuáles serán "erradicados" de su carácter contemporáneo. Es decir, incide en la "domesticación del tiempo" de la historia de un Estado-Nación, dislocando ciertos eventos y sujetos en un pasado que no perturbe las ideas de nación que se configuran y se buscan reivindicar en el presente o en su proyección futura. De esta forma, permite crear una "distancia" sobre ciertos elementos, sujetos, prácticas respecto de su mito fundador (Rufer, 2010). Asimismo, la patrimonialización participa en la "burocratización" de una identidad cultural homogénea (Smith, 1991) mediante la exaltación de valores de la identidad/clase dominante que se los universaliza al colocarlos como 
representativos de "todos/as", entendiendo al patrimonio como propiedad colectiva (Bonfil BataIla, 1999-2000). Por lo tanto, la patrimonialización legitima y consolida la idea de nación desde su constitución temporal como espacial.

El proceso de patrimonialización es dinámico y complejo pero no armónico, ya que los lazos con el pasado son reconstruidos, disputados y resignificados al igual que los elementos que se activan como patrimonio. Así también, porque en el proceso de patrimonialización se expresan y reproducen relaciones asimétricas de poder entre los actores que se involucran e intentan participar del proceso, emergiendo diversos tipos de tensiones y conflictos sociales, políticos, económicos, culturales. En este marco, nos interesa analizar algunas de estas tensiones a la luz de los actores que participaron de la conducción de la CNMMLH en Argentina que se exponen a continuación.

\section{Patrimonio, historia y nación desde la CNMMLH}

La CNMMLH es la institución que en Argentina determina qué elementos adquirirán el estatuto de patrimonio (Ley Nacional 12.665). Por lo tanto, la actuación de dicho organismo nos permite indagar, a partir de la selección de los elementos y lugares que realiza, qué territorio y qué individuos son incluidos como parte de la nación. La CNMMLH fue conformada en 1940, luego de haberse propuesto el proyecto de ley en 1938 (Boletín de la CNMMLH 1, 1938; Levene, 1946). Inicialmente, ella estuvo orientada mayoritariamente por historiadores, siendo Ricardo Levene (1885-1959) uno de los más influyentes de su época (Quattrocchi-Woisson, 1995; Suárez y Saab, 2012). Él no solo presentó el proyecto de ley para la creación de la CNMMLH (Levene, 1946), sino que fue su primer presidente entre los años 1940-1946 en un contexto político particular de nacionalismo y fraude electoral (véase Rotman, 2015a). Los otros miembros eran el vicepresidente, el Sr. Luis Mitre y como vocales: Dr. Ramón J. Cárcano, Dr. Tomás R. Cullen, Dr. Enrique Udaondo; Dr. Emilio Ravignani, Sr. Rómulo Zabala, Dr. Benjamín Villegas Basavilbaso, Dr. Luis María Campos Urquiza y el Sr. Alejo González Garaño.

Desde la CNMMLH Levene y su equipo consolidaron una versión de historia e identidad nacional mediante el patrimonio. Con la mirada puesta en Europa priorizaron aquellos objetos y lugares que reflejaban la herencia española (i.e. elementos con estilo y/o de la época colonial así como referentes de la religión católica). Esto puede ser constatado en las declaratorias realizadas entre los años 1940-1946, de 309 bienes reconocidos como patrimonio nacional, 83 -casi un 27\%-correspondían a capillas, catedrales, basílicas, templos o conventos. Asimismo, en las notas publicadas en los Boletines de la CNMMLH se hacía referencia con regularidad a los valores históricos y religiosos de las edificaciones a considerar, además de la preocupación por mantener diversas iglesias y conventos del país. Existía un particular interés en conservar y patrimonializar aquellos localizados en las provincias del norte argentino -por la concentración de inmuebles religiosos de la época colonial- tanto en Salta, Jujuy ${ }^{3}$; como así también en Córdoba ${ }^{4}$, Misiones y Corrientes ${ }^{5}$,

Véase: Boletín CNMMLH 1, 1939: 33, 139, 137; Boletín CNMMLH 2, 1940: 358; Boletín CNMMLH 3, 1941: 484; Boletín CNMMLH 4, 1942: 539; Boletín CNMMLH 5, 1943: 329-333; Boletín CNMMLH 8, 1946: 429.

Boletín CNMMLH 1, 1939: 128; Boletín CNMMLH 2, 1940: 336; Boletín CNMMLH 3, 1941: 476; Boletín CNMMLH 4, 1942: 557; Boletín CNMMLH 6, 1946: 21, 512; Boletín CNMMLH 8, 1946: 364; Boletín CNMMLH 9, 1948: 33; Boletín CNMMLH 12, 1952: 55, 60; Boletín CNMMLH $13,1956: 144,147$. Boletín CNMMLH 1, 1939: 128; Boletín CNMMLH 2, 1940: 338; Boletín CNMMLH 3, 1941: 13, 467; Boletín CNMMLH 4, 1942: 23, 602; Boletín CNMMLH 8, 1946: 28, 439; Boletín CNMMLH 11, 1949: 19, 492. 
donde se habían preservados las construcciones de las Misiones Jesuíticas. El historiador, Secretario de la CNMMLH, Torres Revello (1893-1964) dejaba en claro la relevancia de proteger esas edificaciones como testimonios, ya que el: "Arte europeo y sin ninguna duda español (...) fue el que sirvió de modelo y generó el arte misional o jesuita-guaraní, dotado de características peculiares" (Boletín CNMMLH 1, 1939: 28). De hecho, las misiones jesuíticas de las provincias señaladas fueron declaradas "Lugar Histórico Nacional" entre 1941, 1942 y 1943 (Ley Nacional 90.732, 106.845; Ley Nacional 112.765; Ley Nacional 16.482 respectivamente).

Nos interesa señalar que durante las primeras dos décadas del siglo XX -tras los festejos del Centenario de la Revolución de Mayo en 1910-, historiadores y arquitectos dedicaron una atención especial al estudio del periodo colonial argentino (Martini, 1971). Ello, luego dio lugar a tensiones -y disputas- disciplinares sobre dónde -y cómo- posicionarse para mirar el patrimonio nacional. Las edificaciones coloniales -sean religiosas o no- eran objeto de valorización, no solo por la CNM$\mathrm{MLH}$, como herencia de un modelo de arte europeo como se expresó anteriormente, sino también en el ámbito de la arquitectura pero desde su contexto de producción latinoamericano.

Arquitectos argentinos destacados de la elite social, como Ángel Guido (1876-1960) y Martín Noel (1888-1963), manifestaron su predilección hacia la arquitectura del periodo colonial, dedicando escritos sobre el tema haciendo referencia, en mayor o menor grado, tanto a Argentina como al resto de Sudamérica (Conti, 2009a; García, 2017). De hecho, Guido, Noel y Mario Buschiazzo (19021970), promovieron las primeras acciones de conservación de edificaciones de carácter colonial en el país; aunque algunos se interesaron más por desarrollar la corriente neo-colonial emergida en la década de 1920, siendo Noel uno de sus representantes (Conti, 2009a; Gutman, 1987).

Así, para algunos arquitectos, el interés no radicaba en destacar el periodo colonial como parte de la herencia europea -como sostenía el historiador Ravello-, sino a partir de las particularidades surgidas en Latinoamérica (Conti, 2009a; Gutman, 1987). Este enfoque manifestaba una necesidad de reencontrarse con "lo propio" en contraposición a "lo ajeno" 6 ", definiéndose lo primero como aquello construido antes del siglo XIX, representado por una comunidad -idealizadacarente de conflictos en vínculo con la tierra. Es decir, como una expresión de lo "popular" que se manifestaba libre y creativamente en lo barroco. Mientras que "lo ajeno" reflejaba el liberalismo del siglo XIX, junto a la disgregación social y el conflicto, la dependencia cultural y la destrucción de valores reconocidos como tradicionales (Gorelik y Silvestri, 1988).

Lo colonial era identificado como una expresión de "lo propio" y las interpretaciones señaladas -que tenían lugar en el seno académicos de la elite argentina- generaron una cierta legitimación del estilo como una obra artística e histórica (Gutman, 1987) asociada al genio humano y la historia, dos de las fuentes de autoridad que Prats (2004) coloca como orientadoras de la patrimonialización.

La tensión que emergía ante la valorización y apropiación de lo colonial por diferentes sectores sociales y políticos de la elite, se expresó en los procesos de patrimonialización. Ello provocaba

Cabe señalar que los motivos por valorizar lo "propio" como figuración de lo nacional se vinculaba con la conflictiva situación sobre el proceso de integración social y política que se encontraba el país ante la ola de inmigración, promovida por el gobierno liderado por la elite liberal, la cual no lograban dirimir (Conti, 2009a; Gutman, 1987). 
disputas entre los historiadores y arquitectos que trabajan en la CNMMLH -o como técnicos de la Dirección General de Arquitectura (DGA), quienes realizaban las obras de restauración- poniendo en cuestión el qué y cómo orientar la preservación de determinadas edificaciones coloniales. Por una parte, la mirada de los historiadores materializada en la actuación de la CNMMLH presidida por Levene (1940-1946), promovía la protección de ese tipo de edificaciones anteponiendo la valorización de los hechos pasados que allí habían transcurridos y porque la arquitectura colonial formaba parte de la herencia europea. Por otra parte, la de los arquitectos quienes comenzaban a priorizar el aspecto estético por sobre el histórico del bien, proponiendo la patrimonialización y preservación de aquellas estructuras que se identificaban como representativas, ícono, del género colonial (Schávelzon, 2008).

M. Buschiazzo -técnico de la DGA y adscripto a la CNMMLH durante la conducción de Levene- realizaba informes, producto de sus viajes y observaciones, sobre la preservación de los bienes que debía evaluar, a la vez que proponía estrategias de restauración, muchas de las cuáles terminaba ejecutando. Inicialmente, podemos observar que los informes que él elevaba a la CNMMLH se centraban más en los acontecimientos históricos transcurridos en los lugares visitados, mientras que con el correr de los años su mirada estética fue tomando protagonismo en sus apreciaciones. Así comentaba, en el año 1939, sobre el caso del Convento de San Carlos (provincia de Santa Fe) sobre: "... múltiples méritos [históricos] le han granjeado su bien ganada fama de santuario de la nacionalidad" (Boletín de la CNMMLH 1, 1939: 48). En el informe Buschiazzo detallaba una serie de hechos históricos que habían tenido lugar en el Convento que legitimaban el reconocimiento como patrimonio nacional, por lo que en 1940 fue declarado "Monumento Histórico Nacional" (Ley Nacional 12.648). Posteriormente, él no solo hacía referencia a los valores "históricos" de las edificaciones que le tocaba evaluar, sino que los exaltaba por su carácter "artístico". Así comentaba respecto de un viaje de inspección realizado en Catamarca en el que enfatizaba que esa provincia: "... conserva bastantes elementos de la época colonial, que contribuyen a darle carácter, dentro de la monótona homogeneidad de nuestras ciudades del interior. Sería de lamentar (...) que se perdiese lo que poco que resta de los tiempos virreinales, para ser reemplazado por una arquitectura de pésimo gusto y sin ningún valor nacional" (Boletín de la CNMMLH 3, 1941: 489). En este caso destaca que aquellos edificios coloniales le otorgan "carácter" al conjunto, emitiendo una ponderación estética de la arquitectura más que histórica. De hecho, señala el "pésimo gusto" y "sin valor nacional" de otros tipos de arquitecturas más recientes. A su vez, en el Boletín de la CNMMLH 3, 1941, Buschiazzo dedicó tres informes que describían la arquitectura colonial de países latinoamericanos, como Venezuela, Colombia y Santo Domingo (Boletín de la CNMMLH 3, 1941: 523-524). Cabe señalar que su interés en el arte colonial lo llevó a dedicar varios trabajos sobre el tema. En 1944 y 1947, por ejemplo, publicó el libro "Estudios de arquitectura colonial hispano americana" y "Bibliografía del arte colonial argentino", respectivamente. De hecho, en 1946, cuando se retiró de la CNMMLH, fundó el Instituto de Arte Americano e Investigaciones Estéticas (IAA), dependiente de la Universidad de Buenos Aires.

Por lo tanto, durante la gestión de Levene en la CNMMLH, se comenzaban a expresar algunas tensiones sobre cómo construir lo nacional mediante el patrimonio en torno a: i) la disputa sobre qué disciplina (historia vs. arquitectura) poseía la autoridad suficiente -o "voz autorizada"- para determinar qué patrimonializar (Pagano, 2012). En ese marco, se dirimía: ii) el tipo de criterio a implementar, de priorizar el valor histórico/antiguo al estético/artístico (Schávelzon, 2008: 203, 211); y iii) un cambio en el posicionamiento sobre qué mirar, "lo propio" sobre "lo ajeno". Ello im- 
plicaba que Argentina se identifique como país latinoamericano y no netamente descendiente de "lo europeo".

Estas diferencias de enfoque y posicionamiento interpelaban a los miembros de la CNMMLH, advirtiendo la necesidad de establecer una nueva lectura sobre el patrimonio nacional. Sin embargo, la CNMMLH continúo su actuación durante las décadas sucesivas, pos Levene, con escasas innovaciones en términos teóricos y metodológicos (Collado, 2015; Conti, 2009b; Pagano, 2012; Pérez Winter, 2018; Repetto, 2014; Tartarini, 2014; Uribarren, 2009). Así, la creación de patrimonios desde la CNMMLH en las décadas sucesivas siguió la misma tendencia, por ejemplo, continuar priorizando inmuebles asociados a la religión católica. Durante toda la década de 1950 se declararon 6 edificaciones de 25; en 1960, 11 de 54; en 1970, 21 de 89 y 1980, 22 de 65; es decir, ocupaban entre un $20 \%$ y un $30 \%$ del total de los lugares reconocidos como patrimonio nacional. Mientras algunos arquitectos canalizaron sus inquietudes sobre "lo propio" en otros espacios -como la revista DANA- e instituciones (ej. IAA) (véase Schávelzon, 2008).

En cuanto a los sujetos que se incluían como parte de la "comunidad imaginada", generalmente -y como ocurrió en la gestión de Levene- se declaraban casas o los sepulcros de personalidades blancas, masculinas (los "grandes hombres") pertenecientes a la elite argentina (Pagano, 2012). Por ejemplo, en la década de 1940 se declararon 116 sepulcros de 309, casi un 40\% del total de los bienes declarados. Las mujeres, los pueblos originarios y afroargentinos no tenían lugar en esa concepción de ser nacional argentino, salvo ocasionales excepciones (véase Rotman, 2015a; Schávelzon, 2008: 189). En la década de 1970, por ejemplo, se incorporan algunos sitios arqueológicos de antiguos poblados indígenas, como las "ruinas del km 75" en la Ruta Nacional 5 (provincia de Chaco), destacándose que ellas representan: "un apasionante capítulo del período hispánico del Chaco del siglo XVI" (Decreto Nacional 631/1979) y algunos poblados del noroeste argentino (Decreto Nacional 370/1975). En el primer caso se colocaban esos lugares como representativos de un periodo de la historia argentina "apasionante" del país, pero no como una forma de reconocer la preexistencia de los pueblos originarios en el territorio. Por lo tanto, ellos eran -desde la patrimonialización- dislocados temporalmente, como señala Rufer (2010), de la idea de nación argentina. Es decir, eran "otros" que se hacían presentes en un pasado que no permitía reconocerlos en la constitución actual de la "comunidad imaginada".

Desde la construcción simbólica del territorio nacional, en el Cuadro $\mathrm{N}^{\circ} 1$ podemos apreciar qué provincias fueron consideradas patrimonialmente por la CNMMLH entre 1940 y 1990. En él se puede observar que se privilegió los bienes localizados en la ciudad de Buenos Aires (Capital Federal) y la provincia homónima, además de Mendoza, Salta, Santa Fe y Córdoba. Ellas se encuentran, según los datos oficiales, entre las provincias con mayor concentración poblacional y altos índices de producción (véase https://www.indec.gob.ar/).

En escasas ocasiones se han patrimonializado edificaciones de provincias que han sido histórica y económicamente relegadas por los gobiernos nacionales del país, desde la constitución del Estado-Nación (1860-1890). Estamos haciendo referencia a las áreas que actualmente se reconocen como la provincia de la Pampa, Chaco, Formosa y la Patagonia (Neuquén, Río Negro, Santa Cruz, Chubut y Tierra del Fuego), las cuales -en ese momento- eran consideradas como un "desierto"; término que se utilizaba para identificar los territorios que aún se encontraban bajo dominio indígena. Pensar esas áreas geográficas como desierto era entenderlas como lugares 
vacíos de sujetos y elementos históricos y culturales "civilizados", legitimando -a la elite liberal argentina- el motivo de su ocupación y dominio mediante proyectos que promovieran el "progreso" -económico-capitalista- (Lois, 1999; Zusman, 2000, 2010). En este sentido, no es casualidad que desde los intelectuales que conformaban la nómina de la CNMMLH se reprodujera una desvalorización patrimonial hacia aquellas áreas del país. Esta tendencia, como se puede apreciar en el Cuadro $N^{\circ} 1$, no ocurrió solo durante la década de 1940 sino que se mantuvo hasta la de 1980.

Cuadro $N^{\circ} 1$.

Cantidad de "bienes" declarados por la CNMMLH como patrimonio nacional (1940-1990).

\begin{tabular}{|l|c|c|c|c|c|c|c|}
\hline \multicolumn{1}{|c|}{ Provincias/décadas } & $\mathbf{1 9 4 0}$ & $\mathbf{1 9 5 0}$ & $\mathbf{1 9 6 0}$ & $\mathbf{1 9 7 0}$ & $\mathbf{1 9 8 0}$ & $\mathbf{1 9 9 0}$ & total \\
\hline Buenos Aires & 23 & 5 & 16 & 13 & 16 & 25 & 98 \\
\hline Capital Federal & 104 & 3 & 13 & 16 & 15 & 47 & 198 \\
\hline Catamarca & 7 & - & 2 & 1 & 1 & 9 & 20 \\
\hline Chaco & 4 & - & - & 1 & 2 & - & 7 \\
\hline Chubut & - & - & 1 & 4 & - & 6 & 11 \\
\hline Córdoba & 21 & 3 & 4 & 7 & 6 & 5 & 46 \\
\hline Corrientes & 20 & 1 & 2 & 2 & 2 & 4 & 31 \\
\hline Entre Ríos & 9 & 1 & 1 & 3 & 5 & 2 & 21 \\
\hline Formosa & - & 1 & - & - & 4 & - & 5 \\
\hline Jujuy & 12 & - & - & 4 & - & - & 16 \\
\hline La Pampa & 6 & - & - & - & - & 2 & 8 \\
\hline La Rioja & 5 & - & 4 & 2 & 3 & 11 & 25 \\
\hline Mendoza & 13 & 5 & 2 & 13 & 3 & 9 & 45 \\
\hline Misiones & 6 & - & - & - & 5 & - & 11 \\
\hline Neuquén & 12 & - & - & - & - & 1 & 13 \\
\hline Río Negro & 5 & - & - & - & 3 & 1 & 9 \\
\hline Salta & 20 & 1 & - & 11 & 1 & 5 & 38 \\
\hline San Juan & 8 & 1 & - & 1 & 1 & 3 & 14 \\
\hline San Luis & 3 & - & 1 & 3 & 3 & - & 10 \\
\hline Santa Cruz & 5 & - & 1 & 1 & 2 & 1 & 10 \\
\hline Santa Fe & 20 & 1 & 3 & 2 & 7 & 6 & 39 \\
\hline Santiago del Estero & 8 & 1 & - & 3 & 2 & 3 & 17 \\
\hline Tierra del Fuego & 1 & - & 2 & - & 12 & 14 & 29 \\
\hline Tucumán & 11 & 2 & 1 & 2 & 2 & 6 & 24 \\
\hline Total & 323 & 25 & 53 & 89 & 95 & 160 & 745 \\
\hline
\end{tabular}

Fuente: elaboración propia a partir de la información provista por la CNMMLH.

Así, en el mapa (Figura $\mathrm{N}^{\circ} 1$ ), presentado a modo ilustrativo, podemos observar el nucleamiento del patrimonio nacional en las provincias del centro del país, expresando una jerarquización territorial como señalamos anteriormente. De hecho, si consideramos la cantidad de bienes declarados que se exponen en el Cuadro $N^{\circ} 1$ de las décadas de 1940-1980 que hace un total 585, 224 se localizan en la ciudad y provincia de Buenos Aires. Esto demuestra el orden de relevancia que poseían y aún mantienen como representativos del territorio nacional. Todas estas características señaladas sobre la configuración del patrimonio y su significancia sobre lo nacional, no mostraron 
mayores cambios durante la década de 1980, especialmente durante la última dictadura (19781983), hasta que se retoma la democracia a fines del año 1983.

Figura $\mathrm{N}^{\circ} 1$.

Cantidad de bienes patrimoniales según provincia (1940-1990). Referencias: 1. Jujuy; 2. Salta; 3. Formosa; 4. Chaco; 5. Misiones; 6. Corrientes; 7. Catamarca; 8. Tucumán; 9. Santiago del Estero; 10. La Rioja; 11. San Juan; 12. Córdoba; 13. Santa Fe; 14. Mendoza; 15. San Luis; 16. Entre Ríos; 17 Neuquén; 18. La Pampa; 19. Provincia y ciudad de Buenos Aires; 20. Río Negro: 21. Chubut; 22. Santa Cruz; 23.

Tierra del Fuego.

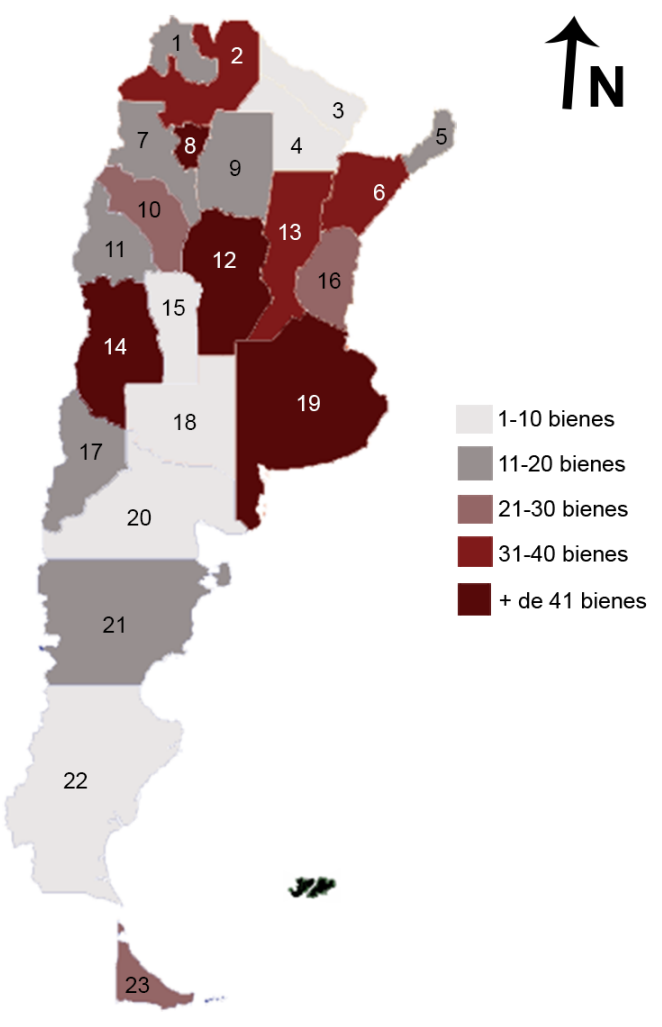

Fuente: elaboración propia a partir de la información provista por la CNMMLH.

\section{La CNMMLH desde la mirada de los arquitectos: ¿una apertura patrimonial y la reconfiguración de lo nacional?}

Con el advenimiento de la democracia la CNMMLH renovó sus autoridades y los/as arquitectos/as se tornaron una presencia significativa desde entonces como presidentes, vocales o delegados provinciales; ; aunque debe destacarse la incorporación de la experticia de profesionales con otras formaciones como arqueología, antropología, abogacía, literatura. Este cambio comen- 
zó a evidenciarse cuando en 1984 el reconocido arquitecto Jorge Enrique Hardoy (1926-1993) asumió como presidente hasta 1993 -año de su fallecimiento-, acompañado por los siguientes vocales: los arquitectos Ramón Gutiérrez, José María Peña, Federico Ortiz, Rodolfo Gallardo y Alberto Nicolini; la arqueóloga Doctora Ana María Lorandi -primera vocal mujer de la CNMMLH- y el Ingeniero Alfredo Bernardini, el doctor Jorge Morello (Actas de la CNMMLH XVII, 1985). Con esta conformación -que luego se iría modificando- se promovió una nueva forma de concebir el patrimonio dentro de la CNMMLH. En este marco queremos señalar un par de puntos. En primer lugar, antes de ocupar la conducción de dicho organismo, Hardoy dedicó parte de sus investigaciones a indagar los procesos de urbanización y planificación en Latinoamérica (Hardoy, 1969, 1972, 1987), llevándolo a interesarse por la protección patrimonial de los centros históricos (Hardoy, 1989; Hardoy y Gutman, 1991; Hardoy et al., 1988). En segundo lugar, durante la década de 1970 persistía en el ámbito académico la necesidad de continuar reivindicando la valorización de la arquitectura argentina en su contexto latinoamericano y mediante una mirada posicionada desde el interior y no centralizada en la ciudad de Buenos Aires (véase Schavelzón, 2008). Hardoy concordaba con estas apreciaciones, recuperándolas en la gestión del patrimonio nacional desde la CNMMLH (Gutiérrez, 1995; Pagano, 2012; Pérez Winter, 2017; Schávelzon, 1993, 2008).

En este marco, la gestión de Hardoy buscó impulsar la "federalización" de la CNMMLH. Este proceso lo orientó mediante diversas acciones. Entre ellas, designó delegados provinciales que informaran y presentaran propuestas de patrimonialización desde el interior del país. A su vez, promovió los vínculos inter institucionales -públicos y privados- con organismos de menor escala territorial (Hardoy, 1989; Hardoy y Gutman, 1991). Así, la CNMMLH se propuso: “...emprender iniciativas para ampliar sus bases de apoyo y el número de socios " (Carta Informativa de la CNMMLH 8, 1986: 2) como los estados municipales. Los vínculos también se establecían mediante la organización de talleres y seminarios de capacitación y valorización del patrimonio a través de la conformación de inventarios (Carta Informativa de la CNMMLH 8, 1986: 4). Con estas acciones la CNMMLH buscaba que la labor sobre qué elementos declarar no sean de su exclusividad, sino también de las delegaciones provinciales -y los estados municipales- a partir de criterios consensuados. Ello implicaba que aquellos bienes que no lograran identificarse como patrimonios nacionales, puedan alcanzar otros marcos de protección locales. Por ello, la CNMMLH impulsó normativas de protección patrimonial provincial y municipal para que, independientemente de la escala de reconocimiento de ciertos elementos, todos aquellos lugares y edificaciones significativos puedan ser resguardados legalmente (Carta Informativa de la CNMMLH 13, 1987). Estas acciones tenían el propósito de evitar que todas las decisiones y resoluciones sobre el patrimonio se formularan desde las oficinas de la CNMMLH en Buenos Aires. Así se sintetizaba el primer año de gestión de Hardoy: "Desde el día 12 de septiembre de 1984 en que asumió el nuevo Presidente, la protección de los bienes culturales de la Nación ha sido encarada con un nuevo enfoque, en el que se destacan el acercamiento del patrimonio cultural a la comunidad, la participación federal y la ampliación del concepto de monumento (...) la participación federal se verifica en la creación de una delegación en cada provincia integrada por delegados elegidos por la Comisión Nacional y un representante elegido por la propia provincia escogidos entre arquitectos dedicados a la preservación urbana, historiadores, arqueólogos y otros especialistas de las respectivas provincias" (Carta Informativa de la CNMMLH 1, 1985 1: 1).

Asimismo, esta nueva CNMMLH reconocía que: "...la Nación contribuyó al equívoco con un criterio auto-limitado de lo que era un "monumento" histórico, fragmentando la comprensión de 
lo cultural con un sesgo demasiado atado a las formas de concebir la historia como una epopeya y proyección de figuras ejemplares. Provincias integradas tardiamente en el proceso de ocupación y colonización como los antiguos territorios nacionales del Nordeste y del Sur del país carecían -en virtud de que sus obras más antiguas pertenecen al siglo XX- de un reconocimiento explícito de lo que significa su aporte cultural al patrimonio nacional" (Carta Informativa de la CNMMLH 13, 1987: 2). Este fragmento expone dos cambios relevantes que tendrán sus implicancias en la espacialización del patrimonio y en ampliar la valorización simbólica del territorio nacional. En primer lugar, se redefinieron las categorías implementadas por la CNMMLH para reconocer los futuros patrimonios y como ejemplo podemos mencionar la ampliación del concepto "monumento". Este ya no sería concebido como un ente aislado sino dentro un contexto: "la idea de monumento aislado se contempla en estrecha relación con su entorno, considerándose como conveniente el rescate de centros históricos ${ }^{8}$ ya que ellos contienen en forma global testimonios que aúnan exponentes arquitectónicos y espacios urbanos que reflejan el desenvolvimiento de una sociedad" (Carta Informativa de la CNMMLH 1, 1985: 2). En segundo lugar, se extendió la escala temporal entendiendo que debían incluirse elementos que evocaran otros momentos de la historia argentina. Así, dejaría de primar solo aquellos hechos correspondientes a los siglos XVIII-XIX, lapso identificado como aquel donde tuvo lugar la conformación del Estado-Nación argentino. De esta forma se anunciaba la patrimonialización de un edificio que representaba: "... un primer exponente de arquitectura del siglo XX que es protegido por la Nación, ratificando el criterio de la Comisión en el sentido de que el patrimonio cultural de los argentinos no reconoce límites cronológicos sino valores históricos y artísticos" (Carta Informativa de la CNMMLH 2, 1885:1). A su vez, se identifica la incorporación de mayor diversidad de bienes como patrimonio nacional. Como ejemplo se puede nombrar: la declaración en 1987 de la "Casa Curutchet" ubicada en la ciudad de La Plata (provincia de Buenos Aires), diseñada por el arquitecto Le Corbusier (1887-1965) -conocido como el "el padre de la arquitectura moderna"- en la década de 1940. En el año 2016 fue reconocida como "Patrimonio de la Humanidad" por la UNESCO. Aquí se incorporó una edificación construida en pleno siglo XX en la que -entre otras cosas- se destacaba por su estilo moderno y no colonial. Otro ejemplo sería la Escuela Provincial de Artes Visuales "Profesor Juan Mantovani" (Decreto Nacional 325/1989) -creada en el año 1939- por su función, arquitectura y su integración al resto del conjunto de edificaciones significativas; o la Catedral de la ciudad de Río Gallegos, en la provincia de Santa Cruz, la cual fue reconocida por sus técnicas constructivas y el uso de materiales locales, dejando de primar el valor monumental de las edificaciones (Decreto Nacional Decreto Nacional 325/1989).

Los cambios recién mencionados permitieron incluir "otros" patrimonios que dieran cuenta del proceso de "federalización" de la CNMMLH. Ello promovió una valorización simbólica del territorio nacional más inclusivo y equitativo como se puede observar en el Cuadro $N^{\circ} 2$. En él se puede apreciar el interés de la CNMMLH por reconocer bienes representativos de todas las provincias, especialmente aquellas que habían sido continuamente relegadas, como Formosa y Tierra del Fuego. Asimismo, y en contraste con las décadas anteriores, la diferencia cuantitativa entre la ciudad/provincia de Buenos Aires y el resto de las provincias no muestra una disparidad desmesurada como se expuso en el Cuadro $N^{\circ} 1$.

La relevancia de la valorización patrimonial de los centros históricos se ha desarrollado en otro trabajo (véase Pérez Winter, 2017). 
Cuadro $\mathrm{N}^{\circ} 2$.

Cantidad de bienes declarados por la CNMMLH como patrimonio nacional (1984-1993).

\begin{tabular}{|l|c|c|c|c|c|c|c|c|c|c|c|}
\hline Provincia/Año & 1984 & 1985 & 1986 & 1987 & 1988 & 1989 & 1990 & 1991 & 1992 & 1993 & Total \\
\hline Buenos Aires & - & - & - & 1 & - & 3 & - & - & - & 1 & 5 \\
\hline Capital Federal & - & - & - & - & - & 3 & 2 & - & 1 & 1 & 7 \\
\hline Catamarca & - & - & - & - & - & 1 & - & - & - & 2 & 3 \\
\hline Chaco & - & - & - & - & - & 2 & - & - & - & - & 2 \\
\hline Chubut & - & - & - & - & - & - & 1 & - & - & - & 1 \\
\hline Córdoba & - & - & - & - & - & 1 & - & 1 & - & - & 2 \\
\hline Corrientes & - & - & - & - & - & 2 & - & - & - & - & 2 \\
\hline Entre Ríos & 2 & - & - & - & - & 2 & - & 1 & - & - & 5 \\
\hline Formosa & - & - & - & - & - & 4 & - & - & - & - & 4 \\
\hline La Rioja & - & - & - & - & - & 2 & - & - & - & - & 2 \\
\hline Mendoza & - & - & 1 & - & - & 2 & - & - & - & - & 3 \\
\hline Río Negro & - & - & - & - & - & 3 & - & - & - & - & 3 \\
\hline Santa Cruz & - & - & - & - & - & 1 & - & - & - & 1 & 2 \\
\hline Santa Fe & - & - & - & - & - & 3 & - & - & - & - & 3 \\
\hline Santiago del Estero & & - & - & - & - & 1 & - & - & - & - & 1 \\
\hline Tierra del Fuego & 9 & - & - & - & - & - & - & - & - & - & 9 \\
\hline Tucumán & - & - & - & - & - & 2 & - & - & - & 1 & 3 \\
\hline Total general & 11 & & 1 & 1 & & 32 & 3 & 2 & 1 & 6 & 57 \\
\hline
\end{tabular}

Fuente: elaboración propia a partir de la información provista por la CNMMLH.

Durante la gestión de Hardoy se utilizaron las categorías de "Monumento Histórico Nacional" y "Lugar Histórico Nacional" para reconocer los 57 bienes declarados entre los años 1984-1993 (Cuadro $N^{\circ}$ 2). El año 1989 -final del primer periodo de gestión- fue el más prolífico, más del $50 \%$ de las declaratorias se formalizaron ese año. Ello fue el resultado de las previas investigaciones que se habían realizado desde el inicio de su gestión (Carta Informativa de la CNMMLH 2, 1985).

Por otra parte, nos interesa señalar la puesta en valor de elementos "naturales" localizados en diferentes puntos del país (Carta Informativa de la CNMMLH 7, 1986; Carta Informativa de la CNMMLH 23, 1989). Ello implicó, también como parte del proceso de "federalización", generar vínculos institucionales con otros organismos del Estado -en sus diferentes escalas administrativas-, como ocurrió con la propuesta de trabajo en conjunto con la Administración de Parques Nacionales. La CNMMLH planteaba extender: "... su tarea a campos que trascienden el ámbito de lo histórico y lo artístico para proyectarse en el de las manifestaciones culturales y naturales que abarquen la defensa del paisaje natural, de las costas, de los hitos relevantes de la geografía..." (Carta Informativa de la CNMMLH 7, 1986: 1). Así, se destacaba cómo la ampliación del término patrimonio posibilitó a la CNMMLH lograr: "...precisión en el objetivo de la preservación que ahora dirige a todo el entorno construido que constituye un testimonio de la historia social de nuestro país" (Carta Informativa de la CNMMLH 9, 1986: 2). 
Cabe señalar otros cambios vinculados a consolidar el sentimiento de pertenencia y de "comunidad imaginada" más inclusiva (y diversa), respecto de las gestiones anteriores. Por una parte, se fomentó el involucramiento de las comunidades locales en los procesos de patrimonialización nacional -y su protección- mediante la participación de talleres barriales y escolares (Carta Informativa de la CNMMLH 29, 1992; Hardoy, 1989; Pérez Winter, 2018). Por otra parte, la CNMMLH buscó dar cuenta y reconocer la heterogeneidad dentro de la configuración de lo nacional: "En el presente se busca la construcción de la identidad nacional como pertenencia de toda una sociedad heterogénea que busca comprenderse, expresarse y ser dueña de su pasado y de su futuro" (Carta Informativa de la CNMMLH 33, 1993: 2). Ello posibilitaría visibilizar a los grupos socio-culturales históricamente excluidos, sosteniendo que el patrimonio: "... no se agota en el tiempo y el espacio, también abarca la representación de bienes representativos de los modos de vida de distintas expresiones sociales" (Carta Informativa de la CNMMLH 2, 1985: 4). Se puede mencionar -a modo de ejemplo- como se expresaba la CNMMLH ante los hallazgos de ocupación indígena en parte del área céntrica de la ciudad de Buenos Aires: "... el asumir con conciencia la existencia de estos materiales arqueológicos de cuatro siglos bajo Buenos Aires (...), da una nueva perspectiva a la responsabilidad del Estado y sus particulares. La Comisión Nacional de Museos, Monumentos y Lugares Históricos asume esa una nueva tarea, dándole un sentido más amplio a la preservación de nuestra herencia cultural" (Carta Informativa de la CNMMLH 30, 1993: 2). Así, la CNMMLH se interesaba por la valorización de ciertos elementos histórico-culturales ubicados en diferentes puntos del territorio (véase Carta Informativa CNMMLH 28, 1990), en los cuales se incluía el "pasado hispano-indígena" y reconociendo la pre-existencia de los pueblos originarios como sujetos históricos.

Estas aperturas territoriales, temporales, socio-culturales y profesionales sobre el patrimonio que expresan la "federalización", son las que posibilitaron el pensar y gestionar de otra forma el patrimonio desde la CNMMLH y que se formalizaron mediante las Disposiciones Internas 5 y 6 del año 1991. Ambas normativas redefinieron y ampliaron "el campo patrimonial" nacional a partir de tres criterios: a- el temporal, el cual refiere a considerar elementos y lugares desde la etapa prehispánica hasta la actualidad; b- el espacial, en el que se incluye el ámbito rural y natural, el entorno físico-ambiental, conjuntos arquitectónicos, pueblos, barrios; y c- el social, al reconocer a todos los "componentes sociales" como creadores de cultura, entendiendo que sujetos de diferentes ámbitos sociales, culturales y económicos generan y producen potenciales patrimonios (Rotman, 2012; Pérez Winter, 2017, 2018). La Disposición Interna 5/1991 habilitaba a la CNMMLH a reconocer una mayor variedad de elementos representativos de otros sujetos -diferentes grupos hacedores de cultura-, tipo de estilos arquitectónicos y etapas productivas -edificaciones de producción industrial, ex-centros de tortura-; localizados en diferentes ámbitos antes desestimados, como patrimonio de la nación.

Es interesante destacar que estas primeras muestras de ampliación del campo patrimonial -que intentaron mantenerse durante la década de 1990- se dieron, en primer lugar, con la recuperación del régimen democrático en el país y, en segundo lugar, bajo un marco neoliberal y de apertura económica. En este último, a nivel nacional, la cultura dejó de ocupar un lugar relevante en la agenda del gobierno (Antonelli, 2004; Getino, 1995; Wortman, 1997). Las medidas implementadas tendieron a: generar un alto grado de mercantilización; desregular la gestión de la producción cultural (Bayardo et al., 1998), lugar que comenzó a ser delegado a empresas privadas al crear e implementar la ley de Mecenazgo (Yúdice, 2001). En este marco, emergieron proyectos de revitalización de los centros urbanos, enfatizando la recuperación de los denominados "grandes 
contenedores". Por ejemplo, las reformas realizadas en varias edificaciones ubicadas en Puerto Madero o las intervenciones en la Casa de Gobierno, la Catedral Metropolitana, el Palacio de Justicia, el Teatro Colón, el Palacio de Congreso, el Abasto y el barrio de San Telmo, correspondientes a la ciudad de Buenos Aires (Arias Inconllán, 1994; Carman, 2005; Carril, 2008; Gómez, 2005; Grillo y Lacarrieu, 1996). De hecho, la CNMMLH tuvo que enfrentar diversas situaciones como la de formular y defender leyes que promovieran la protección de áreas históricas para evitar la demolición de edificaciones significativas ante empresarios y otros actores que buscaban llevar adelante negocios inmobiliarios (Carta Informativa de la CNMMLH 26, 1989). Por otra parte, el periodo señalado también se caracterizó por un interés a escala global por difundir y promover discursos sobre la "diversidad cultural" (Lins Ribeiro, 2014). En ese contexto, en el año 1994, con la modificación de la Constitución Nacional, se expresaba -en el cap. II, art. 41- que el patrimonio es un derecho colectivo enfatizando la necesidad de su preservación, además de reconocer "la pre-existencia étnica y cultural" de los pueblos originarios en el país (art. 75, inciso 17).

En el año 1993 Hardoy fallece y la CNMMLH señaló su gestión como: “... un sistema democrático de trabajo, una visión federal de la cultura y el respeto absoluto a las identidades múltiples que conforman la Nación" (Carta Informativa CNMMLH 34, 1993: 2). Estos principios son los que se buscaron mantener durante la década de 1990. La gestión iniciada en el año 1995, sostenía que: “La concepción del patrimonio cultural de una nación que implicaban meramente la conservación de monumentos y obras de artes, vinculadas a menudo con un criterio de selectividad que privilegiaba ciertos bienes culturales y excluía otros de visiones históricas parciales, debieran hoy ser redefinidas en función de las demandas históricas, sociales y comunicacionales de este fin de siglo en la Argentina" (Carta Informativa de la CNMMLH 36, 1995: 2). Así, con sus particularidades, la CNMMLH continuó reconociendo diversos elementos -que evocan diferentes momentos históricos y pasados- correspondientes a diferentes provincias antes relegadas, como las estaciones de ferrocarril de la línea Gral. Belgrano en la provincia de Formosa (Ley Nacional 24.882/1997) o la cárcel de Reincidentes localizada en Tierra del Fuego (Decreto Nacional 24.818/1997). A su vez, la apertura patrimonial -e ideológica- de la CNMMLH también ha permitido la inclusión de diversos ex-centros clandestinos de detención que funcionaron durante la última dictadura militar argentina (1974-1983), varios de ellos resignificados como lugares de la memoria (Decreto Nacional $1.333 / 2008 ; 1.762 / 2014 ; 1.616 / 2015)$, sean reconocidos como patrimonios nacionales.

\section{Consideraciones finales}

En este artículo hemos analizado la patrimonialización como dispositivo que opera en la legitimación (y actualización) de la idea de nación. En este caso analizamos cómo en Argentina la actuación de la CNMMLH ha participado en la configuración de patrimonios nacionales, determinando el qué, quiénes, cuándo y dónde de una nación. En diferentes contextos, la patrimonialización ha tendido a consolidar distintas versiones del pasado, la identidad, y el territorio -mediante el juego olvido/conmemoración, exclusión/inclusión- que permiten consolidar un tipo de "comunidad imaginada" y sus límites simbólicos territoriales.

Durante la primera etapa de gestión de la CNMMLH, al mando de Levene, se buscó promover la idea de nación anclada en lo europeo, los "grandes hombres" y sus "glorias", como elementos primordiales, tal como Renan advertía necesario para promover sentimientos de devoción hacia 
la patria y lograr anteponer el bien colectivo por sobre el individual. En cuanto a la valorización simbólica del territorio nacional mediante el patrimonio, es interesante destacar la inclusión de un espacio limitado, circunscripto a las áreas donde las poblaciones originarias habían sido diezmadas tempranamente, marginalizando las que fueron incorporadas durante fines del siglo XIX, como era el caso del Chaco, La Pampa y Patagonia. Estas características predominaron, con algunas particularidades, durante las siguientes gestiones hasta mediados de la década de 1980.

Cabe señalar que, aunque la CNMMLH durante la época de Levene se encontraba compuesta por miembros de la elite socio-económica del país, lo que podría suponer la construcción favorable de ciertos consensos, ello no implicó un proceso de gestión patrimonial carente de tensiones (Schavelzón, 2008). Hemos señalado los conflictos político-ideológicos sobre lo nacional a partir de la discusión que se desarrolló entre "lo propio" y "lo ajeno" en el seno académico de la arquitectura y como ello incidió en la gestión de la CNMMLH. Las discusiones sobre "lo propio" y "lo ajeno" impulsaron la valorización del arte colonial argentino, entendido en su contexto de producción latinoamericano. Ello produjo tensiones entre dos sectores que poseían gran relevancia en la preservación del patrimonio nacional, poniendo en cuestión quién debía detentar la "voz autorizada" (historiador vs. arquitecto) sobre cómo y qué conservar. Por lo tanto, la construcción del patrimonio ha sido disputada y tensionada en el interior de la propia institución a partir de dos lecturas vinculadas a la formación de los miembros que la fueron componiendo y de los modelos de país que se estaban proyectando. Estas lecturas fueron las que, en parte, acompañaron el proceso de resignificación de la idea de nación a través del patrimonio.

Con el ingreso de Hardoy en la CNMMLH, se inicia una nueva etapa de aperturas: la "federalización" del patrimonio nacional. Ello introdujo cambios en términos de qué reconocer, quiénes podrían participar en el proceso, qué lugares y narrativas históricas tendrían lugar. Durante 1984 y 1993 se observa la inclusión de diversos patrimonios localizados casi equitativamente en el territorio nacional. Las aperturas patrimoniales también reconfiguraron el quiénes de la comunidad imaginada argentina.

Los criterios de valorización patrimonial han cambiado desde los orígenes de la CNMMLH, no obstante, algunos persisten y son reinterpretados por quienes actúan dentro de dicha institución. Actualmente, la conformación de patrimonios se encuentra legitimada por la mirada ofrecida por los/las aquitectos/as. Sin embargo, la CNMMLH es un organismo en el que se tensionan las subjetividades de quienes la componen, siguiendo sus propias ideologías, formaciones y, sobre todo, los lineamientos políticos que se determinan en cada gobierno (Schávelzon, 2008). Por ello, consideramos relevante entender a la patrimonialización como dispositivo de configuración/ resignificación de la idea de nación, que promueve la sustentación de un mito fundante que oculta -en mayor o menor grado- discontinuidades temporales y espaciales, en, como señala Rufer (2010), una "doble negación". Por una parte, al no reconocer áreas ni sujetos como históricos y modernos. Y, por otra, si los reconoce, la patrimonialización tiende a promoverlos bajo ciertos términos que no dejan de reproducir condiciones desiguales. Ello anima a mantener una idea restringida que permea en el cómo pensar y pensarse dentro de la "comunidad imaginada" de un Estado-Nación en constante reformulación.

Rufer (2010) sostiene que el mito de origen de la nación -en relación con los procesos coloniales- se funda en una "doble negación". Así como la nación no reconoce el pasado de ciertos sujetos, tampoco reconoce el proceso de producción de aquellos discursos que omiten o invisibilizan a esos sujetos, como sujetos históricos. 


\section{Bibliografía}

ANDERSON, B. Comunidades imaginadas. Reflexiones sobre el origen y la difusión del nacionalismo. $2^{\circ}$ ed. Buenos Aires: Fondo de cultura económica, 2011.

ANTONELLI, M. A. Umbrales de una mutación. Retóricas, rituales y escenas del neoliberalismo en Argentina. Guaragua, 2004, N 9, p. 55-66.

ARANTES, A. Produzindo o Passado. En: ARANTES, A. Estrategias de construção do patrimônio cultural. San Pablo: Brasiliensis, 1984, p. 23-58.

ARIAS INCONLLÁN, M. N. Reflexiones acerca de la revitalización de Centros Históricos en la Argentina. En: Seminario Taller. Rehabilitación integral en áreas o sitios Históricos Latinoamericanos. Quito: Abya- Yala, 1994, p. 27-38.

BAYARDO, R., LACARRIEU, M. Y ROTMAN, R. Cultura y políticas culturales en los tiempos del menemismo. Buenos Aires: Mimeo, 1998.

BHABHA, H. Introduction: narrating the nation. En: BHABHA H. Nation and narration. Londres: Routldege, 2000, p. 1-7.

BILLIG, M. Banal Nationalism. 2ºd. Londres: Sage, 2002.

BONFIL BATALLA, G. Nuestro Patrimonio Cultural: un Laberinto de Significados. Revista Mexicana de Estudios Antropológicos, 1999-2000, Nº XLV-XLVI, p. 16- 39.

BOURDIEU, P. The economics of linguistic Exchanges. Social Sciences Information, 1972, N 16, p. 645-668.

CARMAN, M. El barrio del Abasto, o la invención de un lugar noble. Runa, 2005, № 5, p. 79-96.

CARRIL, M. Panorama de la conservación del patrimonio en la Argentina. La obra nueva en entornos heredados. Tesis de Licenciatura. Universidad de Belgrano: Buenos Aires. 2008.

COLLADO, A. El patrimonio en Argentina. Tiempos, espacios y renovación conceptual. Joehlo, 2015, No 6, p. 69-77.

CONTI, A. La construcción del concepto de patrimonio en Argentina entre 1910 y 1940. Anales Linta, 2009a, N 4, p.1-10.

CONTI, A. Against Cosmopolitanism Historic Preservation and the Construction of Argentinean Identity. Future Anterior, 2009b, № 6, p. 1-13.

ERIKSEN, T. H. Ethnicity and nationalism. Anthropological perspective. 3 ed. Nueva York: Pluto Press, 2010. 
FLORESCANO, E. El patrimonio cultural de México. $1^{\circ}$ ed. México: FCE, 1993.

GARCÍA, G. Estrategias institucionales en torno a Bibliografía de arte colonial argentino, de Mario Buschiazzo (1947). Hist. Historiogr, 2017, № 25, p. 10-25.

GARCÍA CANCLINI, N. Culturas Híbridas. Estrategias para entrar y salir de la modernidad. $2^{\circ}$ ed. Barcelona: Paidós, 2010.

GARCÍA FANLO, Luis. ¿Qué es un dispositivo? Foucault, Deleuze, Agamben. A parte Rei, revista de Filosofía, 2011, N 74, p. 1-8.

GELLNER, E. Nación y nacionalismos. 3 ed. Madrid: Alianza, 2001.

GETINO, O. Las industrias culturales en la Argentina. Dimensión económica y políticas públicas. $1^{\circ}$ ed. Buenos Aires: Colihue, 1995.

GIMÉNEZ, G. Para una concepción semiótica de la cultura. 1º ed. México: Mimeo, 1982.

GÓMEZ, S. Patrimonio, turismo y renovación: Políticas de desarrollo turístico en la zona sur de la Ciudad de Buenos Aires durante los años noventa. Temas de patrimonio, 2005, №12, p. 47-65.

GOODENOUGH, W. Rethinking "Status" and "Role": Toward a General Model of the Cultural Organization of Social Relationships. En: BANTON, M. The Relevance of Models for Social Anthropology. Londres: Tayistcok, 1965, p. 1-25.

GORELIK, A. y SILVESTRI, G. Lo nacional en la historiografía de la arquitectura: el peso de la tradición. $1^{\circ}$ ed. Buenos Aires: s/e, 1988.

GRILLO, O. y LACARRIEU, M. San Telmo, ilusión urbana que se vende. Cuicuilco, 1996, № 8, p. 97125.

GUTIÉRREZ, R. Jorge Enrique Hardoy: su aporte a la historia urbana de América Latina. Eure, 1995, $N^{\circ} 21$, p. 9-15.

GUTMAN, M. Noel: ese desconocido. Anales del Instituto de Arte Americano e Investigaciones estéticas, 1987, N²5, p. 90-112.

HARDOY, J. E. La urbanización en América Latina. $1^{\circ}$ ed. Buenos Aires: Instituto Torcuato Di Tella, 1969.

HARDOY, J. E. Las ciudades de América Latina, seis ensayos sobre la urbanización contemporánea. $1^{\circ}$ ed. Buenos Aires: Paidós, 1972.

HARDOY, J. E. Los planos de ciudades coloniales latinoamericanas y sus autores. Anales del Instituto de Arte Americano e Investigaciones estéticas, 1987, № 25, p. 13-28. 
HARDOY, J. E. Los pueblos históricos de América Latina. Medio Ambiente y Urbanización, 1989, Nº 27, p. 1-9.

HARDOY, J. E. y GUTMAN, M. The rol of municipal government in the protection of historic centres in Latin American cities. Environment and Urbanization, 1991, N 3, p. 96-108.

HARDOY, J. E., MADREA, L. y TARTARINI, J. Pequeños poblados históricos: Conservación y rehabilitación integral. DANA, 1988, N²5, p. 92-107.

HOBSBWAM, E. Nations and nationalism since 1780. Programme, myth, reality. $2^{\circ}$ ed. Cambridge: Cambridge University Press, 2000.

LEVENE, R. La cultura histórica y el sentimiento de la nacionalidad. $1^{\circ}$ ed. Buenos Aires: Austral, 1946.

LINS RIBEIRO, G. La Diversidad Cultural como discurso global. Balajú, 2014, №1, p. 17-54.

LOIS, C. La invención del desierto chaqueño. Una aproximación a la apropiación simbólica de los territorios del Chaco en los tiempos de formación y consolidación del estado nación argentino. Scripta Nova, 1999, № 38.

MANTECÓN, A. R. Presentación. El patrimonio cultural. Revista Alteridades, 1998, № 16, p. 3-9.

MARTINI, J. Notas para una crítica de la arquitectura colonial argentina. Anales del Instituto de Arte Americano e Investigaciones estéticas, 1971, № 24, p. 11-25.

ORTEGA VALCARCEL, J. El patrimonio territorial: el territorio como recurso cultural y económico. Ciudades, $1998, N^{\circ} 4$, p. 33-48.

PAGANO, N. La cultura histórica argentina en una perspectiva comparada. La gestión de la CNMMyLH durante las décadas de 1940-1990. En: Il Congreso Internacional de Filosofía de la Historia Dimensiones de la experiencia histórica, Buenos Aires, 2012.

PAGANO, N. y RODRÍGUEZ, M. Conmemoraciones, patrimonio y usos del pasado. La elaboración social de la experiencia histórica. $1^{\circ}$ ed. Buenos Aires: Miño y Dávila, 2014.

PÉREZ WINTER, C. Rehabilitación y patrimonialización de los centros históricos en Argentina: la actuación de la Comisión Nacional de Museos, Monumentos y Lugares Históricos (1980-1990). Revista Andes, 2017, № 28, p. 1-21.

PÉREZ WINTER, C. Patrimonio y patrimonialización en dos "pueblos" de la provincia de Buenos Aires (Argentina). Buenos Aires: Editorial Facultad de Filosofía y Letras, Universidad de Buenos Aires, 2018.

POULOT, D. Uma história do patrimônio no Ocidente. $1^{\circ}$ ed. San Pablo: Estação Liberdade, 2009. 
PRATS, L. Antropología y patrimonio. $2^{\circ}$ ed. Barcelona: Ariel, 2004.

QUATTROCCHI-WOISSON, D. La oficialización de la historia. En: Los Males de la memoria. Historia y política en la Argentina. Buenos Aires: Emecé, 1995, p. 141-162.

RADCLIFFE, S. and WESTWOOD, S. Remaking the nation. Place, identity and politics in Latin America. $1^{\circ}$ ed. Londres: Routleged, 2005.

RENAN, E. What is a nation? En: BHABHA, H. Nation and narration. Londres: Routldege, 2000, p. 8-22.

REPETTO, J. M. La Ley No 12.665 y su necesaria actualización. En: DELHEYA, P. ICOMOS Argentina 40 años. Buenos Aires: Asociación Civil para la Conservación de Monumentos y Sitios Patrimoniales, 2014, p. 157-160.

ROTMAN, M. Dinámica de los inicios institucionales del campo patrimonial nacional. Regulaciones legales y primeros lineamientos de un organismo rector de Patrimonio. En: XXVIII Reunião Brasileira de Antropologia (ABA). San Pablo, 2012.

ROTMAN, M. La "Comisión Nacional de Museos y de Monumentos y Lugares Históricos": proceso de un ámbito institucional de construcción y gestión de patrimonio y su dimensión política. En: DAIBERT SALOMÃO DE CAMPO, Y. Patrimônio Cultural Plural. Belo Horizonte: Arraes Editores, 2015a, p. 191-208.

ROTMAN, M. Procesos de patrimoniales: redifiniciones, dinámicas y tensiones en la contemporaneidad. Que haceres, 2015b, N²2, p.11-26.

RUFER, M. La temporalidad como política: nación, formas de pasado y perspectivas poscoloniales. Memoria y sociedad, 2010, No 14, p. 11-31.

SCHÁVELZON, D. Jorge Hardoy y la preservación patrimonial. Medio ambiente y urbanización, 1993, No II, p. 96-102.

SCHÁVELZON, D. Mejor olvidar. La conservación del patrimonio cultural argentino. $1^{\circ}$ ed. Buenos Aires: Academia de Historia de la Ciudad de Buenos Aires, 2008.

SMITH, A. National identity. $1^{\circ}$ ed. Londres: Penguin, 1991.

SMITH, L. Uses of Heritage. $1^{\circ}$ ed. Londres: Taylor \& Francis e-Library, 2006.

SUÁREZ, C. y SAAB, J. El Estado, Ricardo. Levene y los lugares de memoria. Clío \& Asociados, 2012, No 16, p. 211-227.

TARTARINI, J. La Comisión Nacional de Museos, Monumentos y Lugares Históricos. En: DELHEYA, P. ICOMOS Argentina 40 años. Buenos Aires: Asociación Civil para la Conservación de Monumentos y Sitios Patrimoniales, 2014, p. 185-188. 
URIBARREN, S. La Comisión Nacional de Museos y Monumentos y Lugares Históricos de la Argentina entre 1938-1946. Cuadernos de Historia, 2009, № 11, p. 213-244.

WORTMAN, A. Nuevos sentidos de la palabra cultura en la sociedad argentina del ajuste. Estudios Sociales, 1997, N VII, p. 59-84.

YÚDICE, G. La reconfiguración de políticas culturales y mercados culturales en los noventa y siglo XXI en América Latina. Revista Iberoamericana, 2001, N LXVII, p. 639-659.

ZUSMAN, P. Desierto, Civilización, Progreso. La Geografía del Gran Chaco y el proyecto político territorial de la formación del Estado Argentino. Eria, 2000, № 51, p. 60-67.

ZUSMAN, P. La alteridad de la nación. La formación del Territorio del Noroeste del Río Ohio de los Estados Unidos (1787) y de los Territorios Nacionales en Argentina (1884). Doc. Anàl. Geogr., 2010, $N^{\circ} 56 / 3$, p. $503-524$. 
